\title{
Total carbon dioxide emissions from ground source heat pump and groundwater one in Białystok
}

\author{
Andrzej Gajewski ${ }^{1, *}$ \\ ${ }^{1}$ Bialystok University of Technology, Faculty of Civil Engineering and Environmental Engineering, \\ Department of HVAC Engineering, ul. Wiejska 45a, 15-351 Białystok, Poland
}

\begin{abstract}
To limit greenhouse gases emissions caused by energy production European Union (EU) prompts heat pump as heat generator which should decrease $\mathrm{CO}_{2}$ emissions to the atmosphere. Because of the climatic conditions and low efficiency of electrical energy production and transfer in Poland it could be possible a condensing gas boiler would emit less $\mathrm{CO}_{2}$. The analysis includes ten-year temperature measurements in Białystok where is more severe climate in Poland. Due to relatively high seasonal coefficient of performance (SCOP) value heat pumps can emit less $\mathrm{CO}_{2}$ than condensing gas boiler and can be applied as ecological heat generators.
\end{abstract}

\section{Introduction}

Temperature rise which has been observed on the land part of the Earth at the end of the second millennium, started a discussion its origin. By a common agreement of the majority of the states the greenhouse gases (methane, carbon dioxide, water vapour, ozone, nitrous oxide, halogenated hydrocarbons, etc.) emissions are blamed global warming. Isasmuch as, carbon dioxide concentration has been increasing from $316 \mathrm{ppm}$ [1] at 1960 to $411.69 \mathrm{ppm}$ on $1^{\text {st }}$ April 2019 [2] the limitation of $\mathrm{CO}_{2}$ emissions by minimum $20 \%$ of the 1990 content before 2020 year is a target of European Economic Area states [3]. Thus, EU promptes the exchange heating devices that combust fossil fuels for heat pumps [4].

Although heat pump emit no gases in its location, it uses up electrical energy which is generated in Poland from fossil fuels burning. Moreover, efficiency of electrical energy production in Poland $\eta_{p}=37.6 \%$, as stated by GUS [5], and efficiency of low voltage energy transfer $\eta_{t}=79.2 \%$ which was fixed by Ciura [6]. Overwhelming majority of electrical energy in Poland origins from bituminous coal and lignite combustion, see in Table 2. If we consider efficiency of electrical energy production and transfer, heat pump in Poland is energetically profitable if seasonal coefficient of performance SCOP > 3.5 (cf. Rubik [7], Gajewski et al. [8]). It means, a heat pump which SCOP equals 3.5, generates so much total (in situ plus distant) $\mathrm{CO}_{2}$ emissions as a coal fuel boiler. Thus, it was possible the heat pump would cause

\footnotetext{
*Corresponding author: a.gajewski@pb.edu.pl
} 
more $\mathrm{CO}_{2}$ emissions than a condensing gas boiler (cf. [8]), which is verified using an inequality derived in the paper [8].

$$
\beta_{a}<\beta_{g}=\beta_{n g} \frac{S C O P}{\eta_{b}} \quad\left[k g C O_{2} / G J\right]
$$

where:

$\beta_{a}$ - average value of generation factor for electrical energy production $\left[\mathrm{kgCO}_{2} / \mathrm{GJ}\right]$,

$\beta_{g}$ - green value of generation factor $\left[\mathrm{kgCO}_{2} / \mathrm{GJ}\right]$,

$\beta_{n g}-$ generation factor for natural gas combustion $\left[\mathrm{kgCO}_{2} / \mathrm{GJ}\right]$,

$\eta_{b}$ - efficiency of a condensing gas boiler.

Both $\beta_{a}$ and $\beta_{n g}$ include direct and indirect emissions. If inequality (1) is met then the heat pump is ecologically viable. Otherwise, the condensing gas boiler should be applied.

The aim of research is estimation of emitted $\mathrm{CO}_{2}$ amount to atmosphere during ground to water heat pump (GSHP) and water to water heat pump (WSHP) operation. The first step is determination of seasonal coefficient of performance of GSHP and WSHP, which was done in the work [9]. The second stage which is total $\mathrm{CO}_{2}$ emissions estimation, is presented in the paper.

\section{Computations}

Although an algorithm origins from European standard [10], because of buffer tank operation it must have been changed so as to accurately estimate the heat losses. As the buffer tank is dumped and unloaded, the computations start at midnight on the first day of a heating season and are continued in the consecutive hours until the end of the heating season, which is necessary modification of the standard's algorithm [10]. For that purpose, the mean values of external temperature are calculated in every hour (see in Fig. 1). The external temperature values for ten-year period (2003-2012) at Bialystok weather station were received thanks to kindness of The Institute of Meteorology and Water Management-National Research Institute (IMGW-PIB).

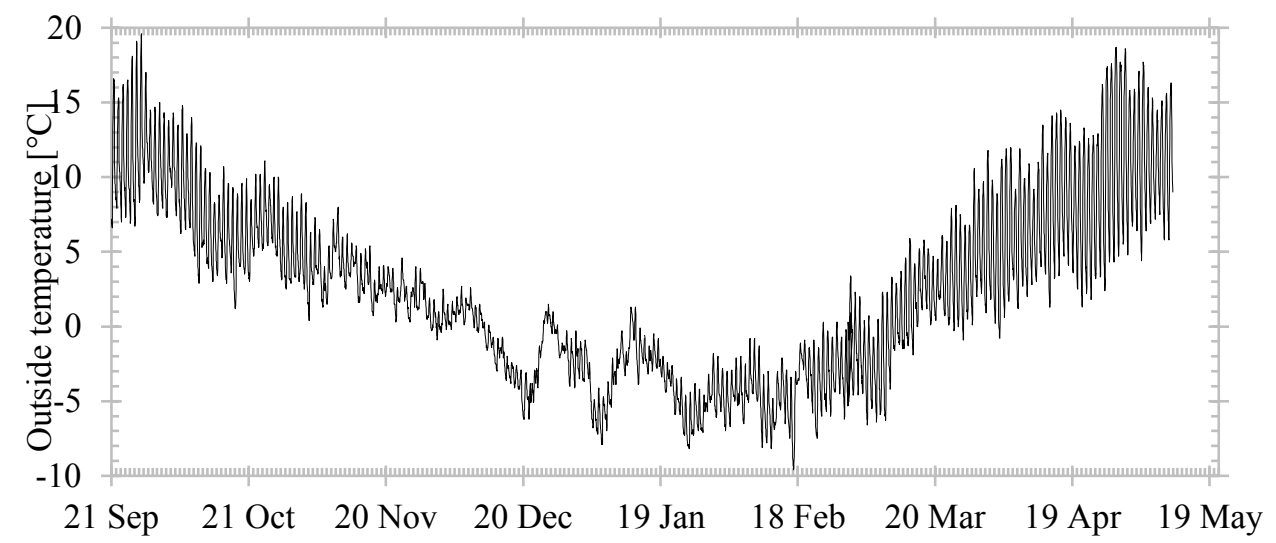

Fig. 1. Mean values of external temperature along heating season.

The comparative calculations are done for a commercial building with total design heat load $Q_{d}=92.73 \mathrm{~kW}$. The building is located in Białystok where the heating season starts on $21^{\text {st }}$ Sepmtember and ends on $10^{\text {th }}$ May. Hence, including a leap day the heating seasons lasts 
5592 hours. Inasmuch as, a leap year occur once per four years a bin hour on $29^{\text {th }}$ Feb $h_{j}=0.25$, on the other days $h_{j}=1$.

There are two alternative heat generators: GSHP or WSHP which the most important data are written down in Table 1. If groundwater composition did not meet the manufacturer's requriements the WSHP circuit should be disjointed from groundwater by a separating heat exchanger (SHE). Thus three variants are taken into consideration: GSHP, WSHP and WSHP+SHE. In every variant heat pump have to be separated from a heating system with a buffer tank (cf. [11]) generating additional losses $Q_{j}$.

Table 1. Technical data of the sized ground and water heat pump units, an extract from a technical guide [11].

\begin{tabular}{|c|c|c|c|}
\hline & & $\begin{array}{c}\text { Vitocal 300-G } \\
\text { Pro type BW } \\
302 . \mathrm{B} 120\end{array}$ & $\begin{array}{r}\text { Vitocal 300-W } \\
\text { Pro type WW } \\
302 . \mathrm{B} 125\end{array}$ \\
\hline Output data to EN 14511 & $\begin{array}{c}\text { B0/W35, } \\
5 \mathrm{~K} \mathrm{spread}\end{array}$ & $\begin{array}{c}\text { W10/W35, } \\
5 \mathrm{~K} \text { spread }\end{array}$ \\
\hline Rated heating output & $\mathrm{kW}$ & 117.2 & 112.1 \\
\hline Power consumption & $\mathrm{kW}$ & 24.4 & 18.3 \\
\hline Coefficient of performance (COP) & - & 4.8 & 6.1 \\
\hline Fluid in primary circuit & & brine & water \\
\hline
\end{tabular}
[10]:

The algorithm starts from part load for heating $P_{h}\left(t_{j}\right)$ determination applying a formula

$$
P_{h}\left(t_{j}\right)=Q_{d} \frac{t_{i}-t_{j}}{t_{i}-t_{e}} \quad[k W]
$$

where

$t_{e}$ is external design temperature,

$t_{i}$ is internal air temperature,

$t_{j}$ is bin temperature (external air temperature).

Electrical energy consumption is predicted using an expression that is extended from the equation in the standard [10] to preseneted hereafter formula that includes heat losses of buffer tank $Q_{j}$ :

$$
E_{e}=\sum_{j=1}^{5592} \frac{h_{j}\left[P_{h}\left(t_{j}\right)+Q_{j}\right]}{C O P_{b i n}\left(t_{j}\right)} \quad[G J]
$$

where $C O P_{b i n}\left(t_{j}\right)$ is obtained from the manufacturer data [11]. Whereas $Q_{j}$. is computed in every hour from a relation:

$$
Q_{j}=\left[i_{k-1}-i\left(20^{\circ} C\right)\right] \rho_{k-1} V\left(1-\eta_{t}\right) \quad[k J]
$$

where:

$i_{k-1}$ - specific enthalpy of water in the buffer tank in a previous hour $[\mathrm{kJ} / \mathrm{kg}]$, $i\left(20^{\circ} \mathrm{C}\right)$ - specific enthalpy of water in the buffer tank at room temperature $[\mathrm{kJ} / \mathrm{kg}]$,

$\rho_{k-1}-$ water density at temperature in a previous hour $\left[\mathrm{kg} / \mathrm{m}^{3}\right]$,

$V$ - buffer tank volume $\left[\mathrm{m}^{3}\right]$,

$\eta_{\mathrm{t}}$ - heat storage efficiency of the buffer tank [-]. 
To correlate bin temperature $t_{j}$ with temperature $t_{k}$ in the buffer tank the latter is obtained from heating curve [11] which is approximated by quadratic polynomial shown in

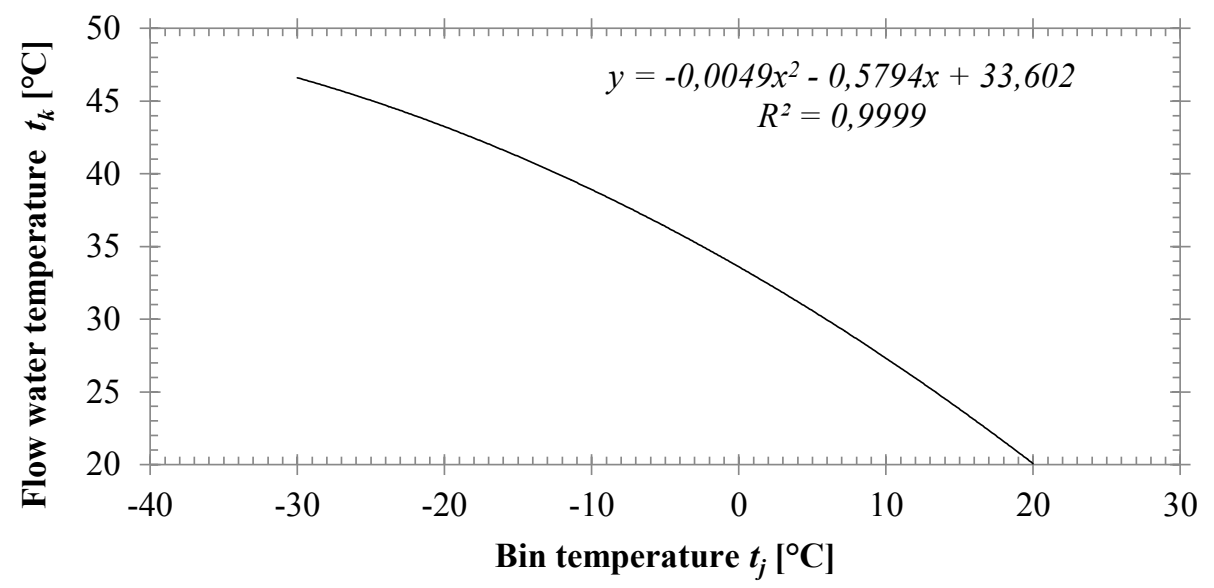

Fig. 2.

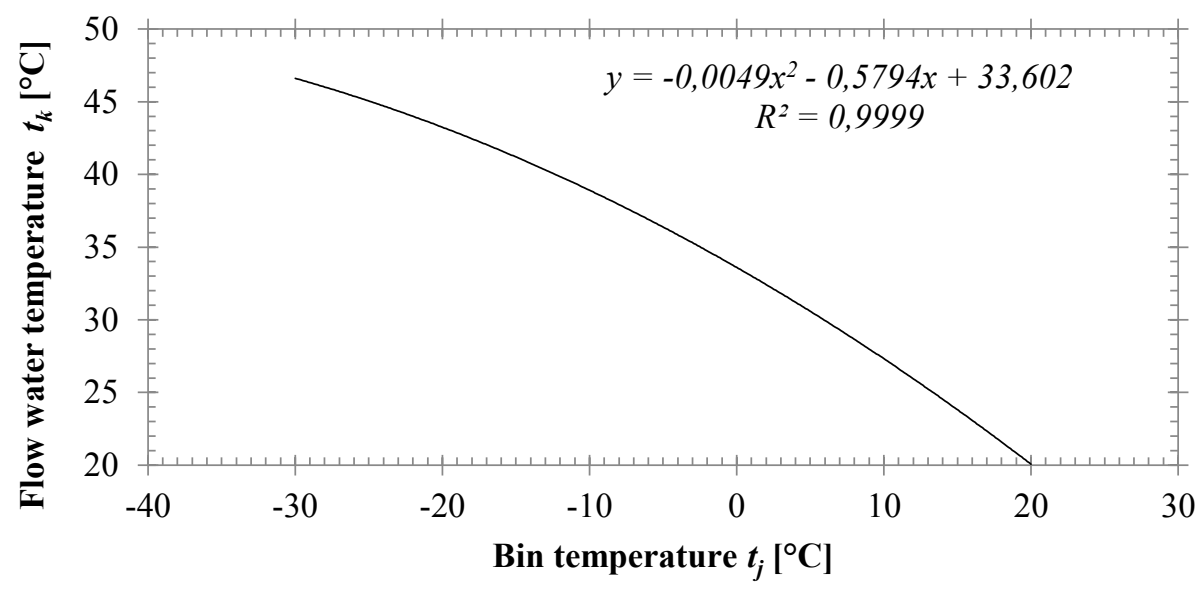

Fig. 2. Heating curve which is assumed in the heating system and its approximated polynomial.

Carbon dioxide emissions $\varepsilon_{\mathrm{CO}_{2}}$ during generation electricity consumed by a heat pump is estimated as follows:

$$
\varepsilon_{C O_{2}}=E_{e} \beta_{a}=E_{e} \frac{\sum \beta_{i} S_{i}}{\eta_{p} \eta_{t}} \quad\left[\frac{k g C O_{2}}{a}\right]
$$

where:

$\beta$ - generation factor of a fuel (cf. Table 2) $\left[\mathrm{kgCO}_{2} / \mathrm{GJ}\right]$;

$S$ - share of the fuel in electrical energy generation (cf. Table 2).

Table 2. The characteristics of electrical energy production in Poland according to PGE-OBRÓT [12].

\begin{tabular}{|c|c|c|}
\hline Fuel & Generation factor $\beta\left[\mathrm{kgCO}_{2} / \mathbf{G J}\right]$ & Share S \\
\hline Bituminous coal & 252.43 & $25.21 \%$ \\
\hline
\end{tabular}




\begin{tabular}{|c|c|c|}
\hline Lignite & 291.95 & $67.70 \%$ \\
\hline Natural gas & 108.28 & $2.95 \%$ \\
\hline Hydropower & 0.00 & $0.85 \%$ \\
\hline Renewables & 0.00 & $2.97 \%$ \\
\hline Others & 6.03 & $0.32 \%$ \\
\hline
\end{tabular}

\section{The results and discussion}

The results are affected by temperature of heat transfer medium. Since ground temperature is slightly lower than groundwater one, GSHP needs more work (electrical energy in the case) than WSHP to provide the same amount of heat. Hence, SCOP $=5.03$ for GSHP is lower than SCOP $=6.12$ for WSHP (cf. the paper [9]). Inasmuch as, SHE decreases brine temperature at $2^{\circ} \mathrm{C}$ in the WSHP circuit SCOP for WSHP+SHE is at 5.86 [9]. It is because each heat exchanger works at a temperature difference. After a substitution the above SCOP values the inequality (1) is verified. The results are plotted in Fig. 3. The relatively high magnitudes of SCOP causes each of analysed variant is ecologically viable as each heat pump would cause less $\mathrm{CO}_{2}$ emissions than condensing gas boiler. It differs from the conclusions in the paper [8], which results from lower COP values in that case. An advantage of the present analysis is caused by the application of hourly measured temperature values.

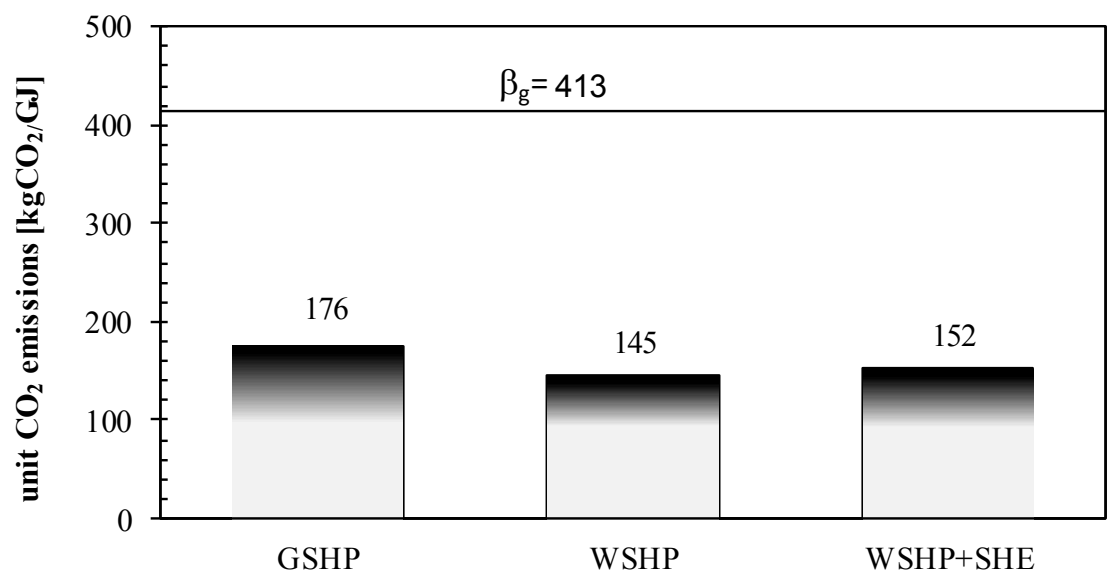

Fig. 3. Unit carbon dioxide emissions for the three analysed variants.

Carbon dioxide emissions which are obtained from eq. (5) after a substitution the magnitudes from Table 2, are presented in Fig. 4. Because of the same reason the highest $\mathrm{CO}_{2}$ amount is emitted during GSHP usage. $18 \%$ less $\mathrm{CO}_{2}$ emissions are caused by WSHP usage. SHE instalation causes $3.7 \%$ higher $\mathrm{CO}_{2}$ production. 


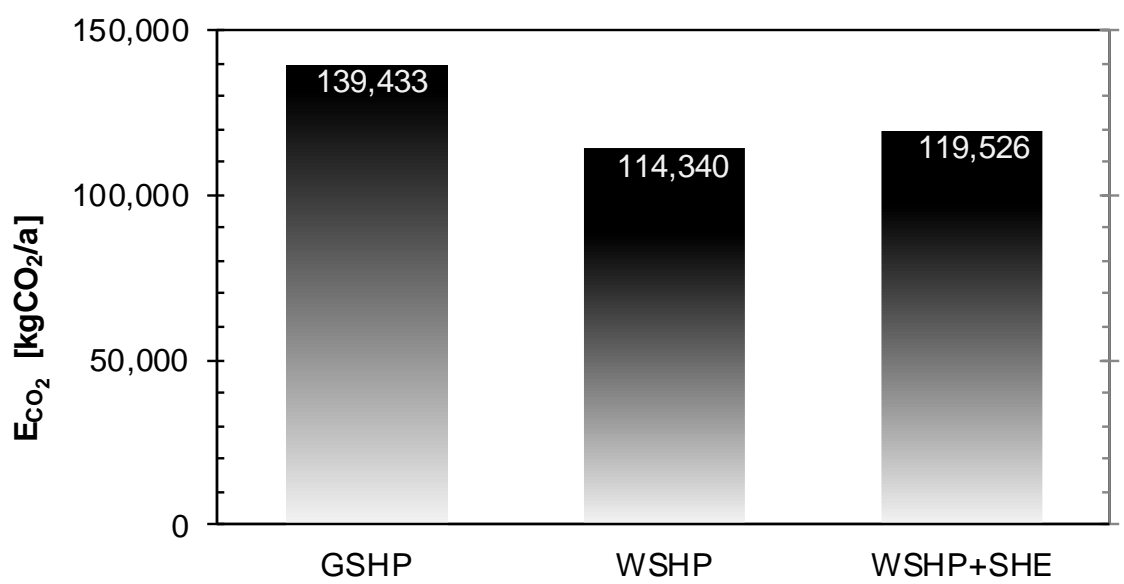

Fig. 4. Annual carbon dioxide emissions for the three analysed variants.

\section{Concluding remarks}

Temperature value at a heating system depends on a heating curve and the weather conditions, which are the same in all the investigated variants. Thus, it does not affect the results of the comparison. As, ground temperature is lower than groundwater temperature in the location, WSHP needs less energy delivered as work. Hence, WSHP causes lesser emissions in a power plant. Although, SHE installation generates a drop in temperature, risen $\mathrm{CO}_{2}$ emissions are lower than in the case of GSHP. After, a detailed analysis of carbon dioxide emissions in Białystok, we are allowed to conclude the ground-water or water-water heat pump can be applied as an ecological heat generator for the heating systems. Although, it is case study, the conclusions may be extended to less severe climatic zones in Poland. The particular decision which kind of heat pump should be applied, depends on a geological case and an economic analysis.

The meteorological data have been available thanks to a kindness of The Institute of Meteorology and Water Management - National Research Institute (IMGW-PIB). Research was carried out at Bialystok University of Technology at Department of HVAC Engineering and it was subsidised by the Ministry of Science and Higher Education Republic of Poland from the funding for statutory R\&D activities. The paper was prepared using equipment which was purchased thanks to either "INNO-EKO-TECH" Innovative research and didactic centre for alternative energy sources, energy efficient construction and environmental protection - project implemented by the Technical University of Bialystok (PB), co-funded by the European Union through the European Regional Development Fund under the Programme Infrastructure and Environment or "Research on the efficacy of active and passive methods of improving the energy efficiency of the infrastructure with the use of renewable energy sources" project was co-financed by the European Regional Development Fund under the Regional Operational Programme of the Podlaskie Voivodship for the years 2007-2013.

\section{References}

1. R. F. Keeling, S. C. Piper, A. F. Bollenbacher, S. J. Walker, Atmospheric CO2 values (ppmv) derived from in situ air samples collected at Mauna Loa, Hawaii, USA (Carbon Dioxide Research Group Scripps Institution of Oceanography (SIO) University of California, February 2009) 
2. U.S. Department of Commerce National Oceanic \& Atmospheric Administration, Global Greenhouse Gas Reference Network, https://www.esrl.noaa.gov/gmd/ccgg/trends/monthly.html [2nd April 2019]

3. European Parliament. Clean energy: the EU's push for renewables and energy efficiency. 2018. Available from:

http://www.europarl.europa.eu/news/en/headlineseconomy/20180109STO91387/ mitigating-climate-change-with-the-eu-s-clean-energy-policy [2018.07.10]

4. Directive 2009/28/EC of the European Parliament and of The Council of 23 April 2009 on the promotion of the use of energy from renewable sources and amending and subsequently repealing Directives 2001/77/EC and 2003/30/EC

5. Energy statistics in 2016 and 2017 GUS (Statistics Poland, Warsaw, 2017)

6. S. Ciura, Energia Elektryczna, 2 (2011)

7. M. Rubik, COW 6, 3-6 (2008)

8. A. Gajewski, J. Siergiejuk, K. Szulborski, Energy Build. 65, 197-204 (2013)

9. A. Gajewski, Seasonal coefficient of performance for ground source heat pump and groundwater one in Białystok (International Conference on Advances in Energy Systems and Environmental Engineering: ASEE17, Wrocław, July 2017)

10. 2017EN 14825:2016 Air conditioners, liquid chilling packages and heat pumps, with electrically driven compressors, for space heating and cooling - Testing and rating at part load conditions and calculation of seasonal performance

11. Viessmann, VITOCAL brine/water and water/water heat pumps, single and two-stage, 89 to $290 \mathrm{~kW}$, Technical guide, May (2013)

12. https://pge-obrot.pl/O-Spolce/Struktura-paliw [02.04.2019] 